\title{
Stark broadening of spectral lines of multicharged ions of astrophysical interest
}

\section{P IV spectral lines ${ }^{\star}$}

\author{
M.S. Dimitrijevic ${ }^{2}$ and S. Sahal-Bréchot ${ }^{2}$ \\ 1 Astronomical Observatory, Volgina 7, 11050 Belgrade, Yugoslavia \\ 2 Laboratoire "Astrophysique, Atomes et Molécules", Département Atomes et Molécules en Astrophysique, Unité associée au \\ C.N.R.S. No. 812, Observatoire de Paris-Meudon, 92190 Meudon, France
}

Received August 7; accepted August 19, 1996

\begin{abstract}
Using a semiclassical approach, we have calculated electron-, proton-, and He III-impact line widths and shifts for $114 \mathrm{P}$ IV multiplets for perturber densities $10^{15}-10^{20} \mathrm{~cm}^{-3}$ and temperatures $T=5000-1000000 \mathrm{~K}$. The obtained results have been compared with results obtained by using various simpler approaches.
\end{abstract}

Key words: lines: profile-atomic data

\section{Introduction}

The Stark broadening parameters of P IV lines are of interest not only for the plasma diagnostic but for the research of regularities and systematic trends and theoretical considerations as well. Consequently, Stark widths for $\mathrm{P}$ IV $4 \mathrm{~s}^{1} \mathrm{~S}-4 \mathrm{p}^{1} \mathrm{P}^{\circ}, 4 \mathrm{~s}^{3} \mathrm{~S}-4 \mathrm{p}^{3} \mathrm{P}^{\circ}$ and $3 \mathrm{p}^{3} \mathrm{P}^{\circ}-3 \mathrm{~d}^{3} \mathrm{D}$ multiplets have been determined (Dimitrijević \& Konjević 1981; Dimitrijević 1988a,b) within the modified semiempirical approach (Dimitrijević \& Konjević 1980), Griem's semiempirical approach (Griem 1968), simplified semiclassical approach (Eq. (526) in Griem 1974) and its modification (Dimitrijević \& Konjević 1980).

This paper is the fifteenth of a series devoted to the calculation of Stark broadening parameters of spectral lines of multicharged ions (see Dimitrijević \& Sahal-Bréchot 1995 and references therein, as well as Dimitrijević \& Sahal-Bréchot 1996a,b). In order to continue our research of Stark broadening parameters needed for the investigation of astrophysical and laboratory plasmas and to

Send offprint requests to: M.S. Dimitrijević

* Table 1 is only available in electronic form: The material published electronically can be accessed: by ftp at cdsarc.ustrasbg.fr or 130.79.128.5 or on WWW at: http//cdsweb.ustrasbg.fr/abstract.html provide the needed Stark broadening data, we have calculated within the semiclassical-perturbation formalism (Sahal-Bréchot 1969a,b) electron-, proton-, and He IIIimpact line widths and shifts for 114 PIV multiplets. The original computer code (Sahal-Bréchot 1969a,b), has been updated and optimized several times (Sahal-Bréchot 1974; Fleurier et al. 1977; Dimitrijević et al. 1991; Dimitrijević \& Sahal-Bréchot 1996c). A summary of the formalism is given in Dimitrijević \& Sahal-Bréchot (1996c).

\section{Results and discussion}

The energy levels for P IV lines have been taken from Martin et al. (1985). Oscillator strengths have been calculated by using the method of Bates \& Damgaard (1949) and the tables of Oertel \& Shomo (1968). For higher levels, the method described by Van Regemorter et al. (1979) has been used.

In addition to electron-impact full halfwidths and shifts, Stark-broadening parameters due to proton-, and He III- impacts have been calculated. Our results for 114 P IV multiplets are shown in Table 1 (published only in electronic form), for perturber densities $10^{15}-10^{20} \mathrm{~cm}^{-3}$ and temperatures $T=5000-1000000 \mathrm{~K}$. We also specify a parameter $c$ (Dimitrijević \& Sahal-Bréchot 1984), which gives an estimate for the maximum perturber density for which the line may be treated as isolated when it is divided by the corresponding full width at half maximum. For each value given in Table 1, the collision volume $(V)$ multiplied by the perturber density $(N)$ is much less than unity and the impact approximation is valid (Sahal-Bréchot 1969a,b). Values for $N V>0.5$ are not given and values for $0.1<N V \leq 0.5$ are denoted by an asterisk. When the impact approximation is not valid, the ion broadening contribution may be estimated by using quasistatic approach (Sahal-Bréchot 1991 and Griem 1974). In the region between where neither of these two 
Table 2. Present semiclassical Stark full widths at half maximum (WDSB) in $\AA$ compared with the calculations of Dimitrijević (1988a,b) by using the modified semiempirical approach (Dimitrijević \& Konjević 1980), Griem's semiempirical approach (Griem 1968), symplified semiclassical approach (Eq. (526) in Griem 1974) and its modification (Dimitrijević \& Konjević 1980)

\begin{tabular}{|c|c|c|c|c|c|c|}
\hline $\begin{array}{l}\text { PERTURBE } \\
\text { TRANSITION }\end{array}$ & $\begin{array}{l}\text { DENSI } \\
\mathrm{T}(\mathrm{K})\end{array}$ & $\begin{array}{l}F Y=1 \cdot E+17 \\
\operatorname{WDSB}(A)\end{array}$ & $w G(A)$ & WGM (A) & WSEM (A) & WSE (A) \\
\hline $\begin{array}{l}P \text { IV } 4 S \text { AP } \\
4250.9 \mathrm{~A} \\
\mathrm{C}=0.43 \mathrm{E}+21\end{array}$ & $\begin{array}{l}10000 \\
20000 \\
40000 \\
80000 \\
160000\end{array}$ & $\begin{array}{l}0.714 \\
0.502 \\
0.367 \\
0.280 \\
0.225\end{array}$ & $\begin{array}{l}0.653 \\
0.477 \\
0.360 \\
0.285 \\
0.238\end{array}$ & $\begin{array}{l}0.363 \\
0.279 \\
0.229 \\
0.202 \\
0.188\end{array}$ & $\begin{array}{l}0.565 \\
0.399 \\
0.282 \\
0.215 \\
0.183\end{array}$ & $\begin{array}{c}0.264 \\
0.186 \\
0.132 \\
--- \\
---\end{array}$ \\
\hline $\begin{array}{l}\text { P IV } 4 S 4 P \\
3356.9 \mathrm{~A} \\
C=0.34 \mathrm{E}+21\end{array}$ & $\begin{array}{l}10000 \\
20000 \\
40000 \\
80000 \\
160000\end{array}$ & $\begin{array}{l}0.411 \\
0.291 \\
0.210 \\
0.159 \\
0.127\end{array}$ & $\begin{array}{l}0.385 \\
0.281 \\
0.211 \\
0.166 \\
0.138\end{array}$ & $\begin{array}{l}0.216 \\
0.165 \\
0.134 \\
0.117 \\
0.108\end{array}$ & $\begin{array}{l}0.330 \\
0.233 \\
0.165 \\
0.121 \\
0.100\end{array}$ & $\begin{array}{l}0.158 \\
0.112 \\
0.790 \mathrm{E}-01 \\
0.648 \mathrm{E}-01 \\
=--\end{array}$ \\
\hline $\begin{array}{c}\text { P IV 3P 3D } \\
826.3 \mathrm{~A} \\
\mathrm{C}=0.46 \mathrm{E}+20\end{array}$ & $\begin{array}{r}10000 . \\
20000 . \\
40000 . \\
80000 \\
160000 .\end{array}$ & $\begin{array}{l}0.743 \mathrm{E}-02 \\
0.521 \mathrm{E}-02 \\
0.375 \mathrm{E}-02 \\
0.271 \mathrm{E}-02 \\
0.200 \mathrm{E}-02\end{array}$ & $\begin{array}{l}0.573 \mathrm{E}-02 \\
0.417 \mathrm{E}-02 \\
0.313 \mathrm{E}-02 \\
0.248 \mathrm{E}-02 \\
0.211 \mathrm{E}-02\end{array}$ & $\begin{array}{l}0.477 \mathrm{E}-02 \\
0.350 \mathrm{E}-02 \\
0.267 \mathrm{E}-02 \\
0.216 \mathrm{E}-02 \\
0.190 \mathrm{E}-02\end{array}$ & $\begin{array}{l}0.350 \mathrm{E}-02 \\
0.248 \mathrm{E}-02 \\
0.175 \mathrm{E}-02 \\
0.124 \mathrm{E}-02 \\
0.873 \mathrm{E}-03\end{array}$ & $\begin{array}{l}0.260 \mathrm{E}-02 \\
0.184 \mathrm{E}-02 \\
0.130 \mathrm{E}-02 \\
0.920 \mathrm{E}-02 \\
0.690 \mathrm{E}-03\end{array}$ \\
\hline
\end{tabular}

approximations is valid, a unified type theory should be used. For example in Barnard et al. (1974), a simple analytical formula for such a case is given. The accuracy of the results obtained decreases when broadening by ion interactions becomes important.

In Table 2, present semiclassical Stark full widths at half maximum (WDSB) in $\AA$ are compared with the calculations in Dimitrijević (1988a,b) by using the modified semiempirical approach (Dimitrijević \& Konjević 1980), Griem's semiempirical approach (Griem 1968), simplified semiclassical approach (Eq. (526) in Griem 1974) and its modification (Dimitrijević \& Konjević 1980). One can see that the best agreement is with the results obtained by using the simplified semiclassical approach.

For further development and refinement of the theory, the corresponding experimental data will be very useful.

Acknowledgements. This work is a part of the project "Astrometrical, Astrodynamical and Astrophysical Investigations", supported by Ministry of Science and Technology of Serbia.

\section{References}

Barnard A.J., Cooper J., Smith E.W., 1974, J. Quant. Spectrosc. Radiat. Trans. 14, 1025

Bates D.R., Damgaard A., 1949, Trans. Roy. Soc. London Ser. A 242,101
Dimitrijević M.S., 1988a, Bul. Obs. Astron. Belgrade 139, 31 Dimitrijević M.S., 1988b, A\&AS 76, 53

Dimitrijević M.S., Konjević N., 1980, J. Quant. Spectrosc. Radiat. Trans. 24, 451

Dimitrijević M.S., Konjević N., 1981, in Spectral Line Shapes, Wende B., de Gruyter W. (eds.) Berlin, New York, p. 211

Dimitrijević M.S., Sahal-Bréchot S., 1984, J. Quant. Spectrosc. Radiat. Trans. 31, 301

Dimitrijević M.S., Sahal-Bréchot S., Bommier V., 1991, A\&AS 89,581

Dimitrijević M.S., Sahal-Bréchot S., 1995, A\&AS 109, 551

Dimitrijević M.S., Sahal-Bréchot S., 1996a, A\&AS 115, 351

Dimitrijević M.S., Sahal-Bréchot S., 1996b, A\&AS 119, 369

Dimitrijević M.S., Sahal-Bréchot S., 1996c, Phys. Scr. 54, 50

Fleurier C., Sahal-Bréchot S., Chapelle J., 1977, J. Quant. Spectrosc. Radiat. Trans. 17, 595

Griem H.R., 1968, Phys. Rev. 165, 258

Griem H.R., 1974, Spectral Line Broadening by Plasmas. Academic Press, New York.

Martin, W.C., Zalubas, R., Musgrove, A., 1985, J. Phys. Chem. Ref. Data 14, 751

Oertel G.K., Shomo L.P., 1968, ApJS 16, 175

Sahal-Bréchot S., 1969a, A\&A 1, 91

Sahal-Bréchot S., 1969b, A\&A 2, 322

Sahal-Bréchot S., 1974, A\&A 35, 321

Sahal-Bréchot S., 1991, A\&A 245, 322

Van Regemorter H., Hoang Binh Dy, Prud'homme M., 1979, J. Phys. B 12, 1073 